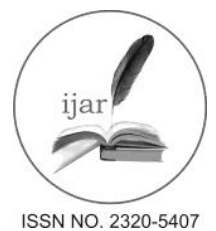

Journal homepage: http://www.journalijar.com Journal DOI: $\underline{\text { 10.21474/IJAR01 }}$

RESEARCH ARTICLE

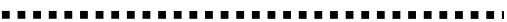
INTERNATIONAL JOURNAL OF ADVANCED RESEARCH

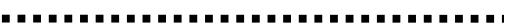

\title{
MICROBIAL ASSESSMENT OF MEAT SOLD IN AROUND THE HYDERABAD CITY.
}

\author{
*B.Srinu ${ }^{1}$, K.Kasturi Devi ${ }^{2}$, T.Madhava Rao ${ }^{1}$, N.Krishnaiah ${ }^{1}$ and L.V.Rao ${ }^{1}$ \\ 1. Dept.of Veterinary Public health, College of Veterinary Science, Korutla-505326, Hyderabad. \\ 2. Dept.of Veterinary Pharmacology \& Toxicology, College of Veterinary Science, Korutla-505326, Hyderabad.
}

\section{Manuscript Info}

\section{Manuscript History:}

Received: 18 April 2016

Final Accepted: 19 May 2016

Published Online: June 2016

Key words:

Food borne pathogens,

antimicrobial agents, retail shops,

Hyderabad city

*Corresponding Author

\section{B.Srinu.}

\begin{abstract}
Food borne pathogens are major causes for the food borne illness in the developing countries due to changing the food habits. The main objective of the present study is to investigate the microbial quality of meat sold in retail shops in around the Hyderabad city and to determining their susceptibility to different antimicrobial agents. A total of 120 samples were collected from the 15 retail shops and are processed and analyzed for potential food borne pathogens using standard methods. Antibiotic susceptibility test was performed by using disk diffusion method. Out of 120 samples $8(6.67 \%)$, $39(32.5 \%)$ and $46(38.33 \%)$ were positive for Salmonella spp., E. coli and Staphylococcus aureus respectively. Antimicrobial susceptibility testing for E. coli showed resistant to Ampicillin, Naldixic acid, Gentamicin, but sensitive to remaining all the antibiotics tested. Among the S. aureus isolates $90 \%$ were resistant to Nitrofurontaine, $80 \%$ to Ampicillin, $68 \%$ to Norfloxicin, $60 \%$ to Cefpodoxime, 38\% to streptomycin, and $20 \%$ to Kanamycin but all (98\%) of the isolates were sensitive to Co-trimoxazole. Whereas, isolates of Salmonella spp. shown resistant to Ampicillin (86\%), Gentamycin (92\%), Tetracycline (78\%) and 60\% to Cefpodoxime but $44 \%$ (17) isolates were sensitive to all the antibiotics tested. Present study concluded that the meat from retail meat shops is important sources of bacteria of public health significance i.e. Salmonella, E.coli and Staphylococci in Hyderabad city. Presence of this pathogenic microorganisms indicating there is a need to screening of meat from the retail shops to monitor hygienic conditions.
\end{abstract}

\section{Introduction:-}

Microbial food safety and food-borne infections are important public health concern worldwide. There have been a number of food-borne illnesses resulting from the ingestion of contaminated foods such as chicken meats. Most of the pathogens that play a role in food borne diseases have a zoonotic origin [Busani et al ,2006]. According to reports of the World Health Organization (WHO, 2003) and the Centers for Disease Control and Prevention (CDC, 2000) every year a large number of people are affected by diseases due to contaminated food consumption. Although, these pathogens usually cause mild to moderate self-limiting gastroenteritis, invasive diseases and complications resulting in more severe cases (Zhao et al., 2001). Numerous epidemiological reports have implicated foods of animal origin as the major vehicles associated with illnesses caused by food-borne pathogens (Peterson et al., 1998). Contaminated raw or undercooked poultry and red meats are particularly important in transmitting these food-borne pathogens (Zhao et al., 2001).

In developing countries potential cause for food borne illnesses are poverty, inadequate sanitary conditions, and poor general hygiene (Siddiqui et al., 2006). Raw meat is available in open-air local retail shops without appropriate temperature control and this is purchased by households. Although, it is difficult to prove a direct role of drug resistance 
in bacteria contaminating food items with increased clinical cases of resistant infections, the presence of such bacteria in food items could play a role in the spread of antimicrobial resistance amongst food-borne pathogens (Farzana et al., 2009). Thus, adequate information should be gathered to develop an effective strategy to reduce the outbreak of food borne illnesses and resistance burden in the community. This study therefore aimed at investigating the microbial quality of meat available in common retail shops in Hyderabad city to determine susceptibility pattern of bacterial isolates.

\section{Materials and methods:-}

This study involved randomly selected 15 butcher shops in Hyderabad city. Samples were collected from meat cutting knife, Scalding tank, and Dressing Table, Platform, Personnel, water and meat samples. For collection of swab samples, sterile cotton swabs $(3 \mathrm{~cm}$ long and $1 \mathrm{~cm}$ in diameter) moistened with 1 percent peptone water was used. Swabs were rubbed on sites continuously for 30 seconds (Morris and Wells, 1970). The samples were collected in sterile container and immediately transported using ice box to the laboratory for bacteriological analysis.

Screw cap tubes containing swabs were shaken on Vortex mixer for 30 seconds for uniform distribution of microorganisms. Tenfold serial dilutions upto $10^{-8}$ dilution of all the samples were done using sterile normal saline solution. A $25 \mathrm{gm}$ sample of the meat was homogenized in $225 \mathrm{ml}$ of buffered peptone water using homogenizer. Then the sample was made into 10 fold serial dilutions and was incubated for $24 \mathrm{hrs}$ at $37^{\circ} \mathrm{C}$. All media and antibiotic discs were purchased from Himedia. For isolation and identification of pathogenic organisms a loopful od sample from homogenate inoculate onto Nutrient agar plates and incubated at $37^{\circ} \mathrm{C}$ for 48 hours. Isolation of specific pathogenic organism's specific Medias is used. For isolation of S. aureus, E.coli and Salmonella spp. a loop full colonies from Nutrient agar plates were inoculated on Manitol salt agar (MSA), Maconkey agar, EMB agar and $\mathrm{XLD}$ agar pates and the plates were incubated at $37^{\circ} \mathrm{C}$ for 48 hours. Formation of golden yellow colonies on MSA which were identified as S. aureus. Then the gram-negative organisms including Salmonella and E.coli were identified by using biochemical reactions. For confirmation of thermo tolerant E. coli; suspected isolates were incubated at $44^{\circ} \mathrm{C}$ water bath for 48 hours in nutrient broth and they were tested for growth at $44^{\circ} \mathrm{C}$ and checked for indole production. Isolates which demonstrated growth at $44^{\circ} \mathrm{C}$ with indole production were confirmed as thermo tolerant. Antimicrobial susceptibility testing for Salmonella, E. coli and S. aureus was performed using the disk diffusion method and results were interpreted using the performance standards for antimicrobial disk susceptibility

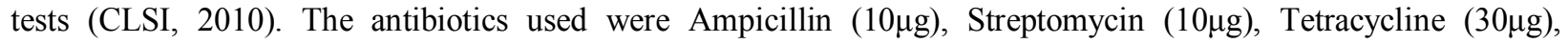

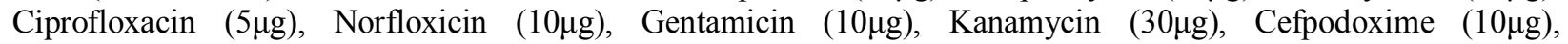
Nitrofurontaine $(300 \mu \mathrm{g})$ and Co-trimoxazole $(25 \mu \mathrm{g})$.

\section{Results and discussion:-}

Food borne illnesses caused by non- typhoid Salmonella, S. aureus and E. coli represents a major public health problem worldwide. These pathogens are transmitted mainly through consumption of contaminated food and water and the presence of these organisms in meat animals and in raw meat products has relevant public health implications (Sousa, 2008) From the present study it was observed that almost all the samples from the retail meat shops had pathogenic microorganisms which are contributing incidence of food borne illness. In this study, pathogenic organisms are isolated in the majority of samples collected from retail meat shops, which indicates the presence of unhygienic food processing. Moreover, the identification of thermo-tolerant E. coli showed the presence of recent fecal contamination (Collee and Mackie, 1999). These findings are in accordance with the findings of Gibbons et al (2006).

A total of 120 samples from 15 butcher shops were collected and analyzed for various food borne pathogens. Among 120 samples 8(6.67\%) were positive for Salmonella spp., 39(32.5\%) were positive for E. coli, whereas 46(38.33\%) samples were positive for Staphylococcus aureus (Table 1). Earlier Lin et al. (2009) and Kumar et al. (2010) were reported Staphylococcal contamination from various sources of slaughter process which are similar to the results of present study.

In the present study Dressing table (6), water (7) and meat (8) were the sources from which high numbers of $E$. coli isolates were obtained. The results are indicative of hygienic conditions of major sources from where $E$. coli contamination in meat food chain takes place. Morar et al. (2008) Studied critical control points (CCP) in poultry slaughterhouse and found that knife, water, table and poultry meat as main source of E. coli. In present study also similar observations were seen.Salmonella spp. was isolated from different sources during the slaughter process and the low salmonella isolation percentage may be due to low level of feacal and water contamination (Valerie et al., 2009). 
Out of the $39 \mathrm{E}$. coli isolates $28(72 \%)$ were thermo-tolerant. Antimicrobial susceptibility testing for E. coli showed resistant to Ampicillin, Naldixic acid, Gentamicin, but sensitive to remaining all the antibiotics tested. A total of 46 S. aureus isolates were tested for ten antibacterial agents which showed $90 \%$ were resistant to Nitrofurontaine, $80 \%$ to Ampicillin, $68 \%$ to Norfloxicin, $60 \%$ to Cefpodoxime, $38 \%$ to streptomycin, and $20 \%$ to Kanamycin but all $(98 \%)$ of the isolates were sensitive to Co-trimoxazole. However, out of the 46 isolates of S. aureus $10(20 \%)$ were sensitive to all the antibiotics tested. Total of 39 isolates of Salmonella spp. were tested for ten antibiotic discs which showed resistant to Ampicillin (86\%), Gentamycin (92\%), Tetracycline (78\%) and 60\% isolated to Cefpodoxime but $44 \%$ (17) isolates were sensitive to all the antibiotics tested. These findings are in accordance with the findings of Haimanot Tassew et al. (2010).

Fig 1.Showing antibiotic sensitivity test of S.aureus. with different antibiotic discs

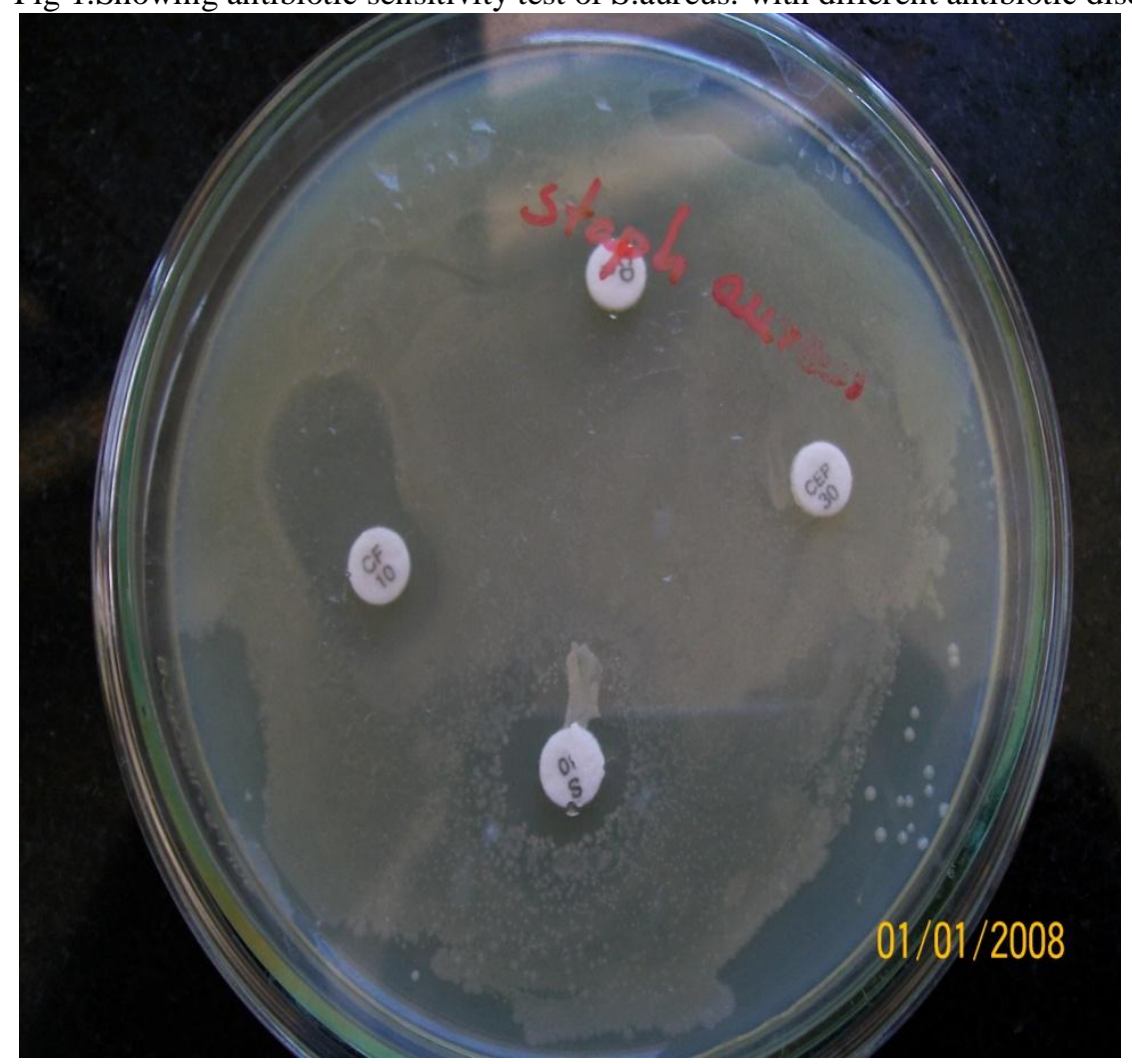


Fig 2. Showing antibiotic sensitivity test of E.coli with different antibiotic discs.

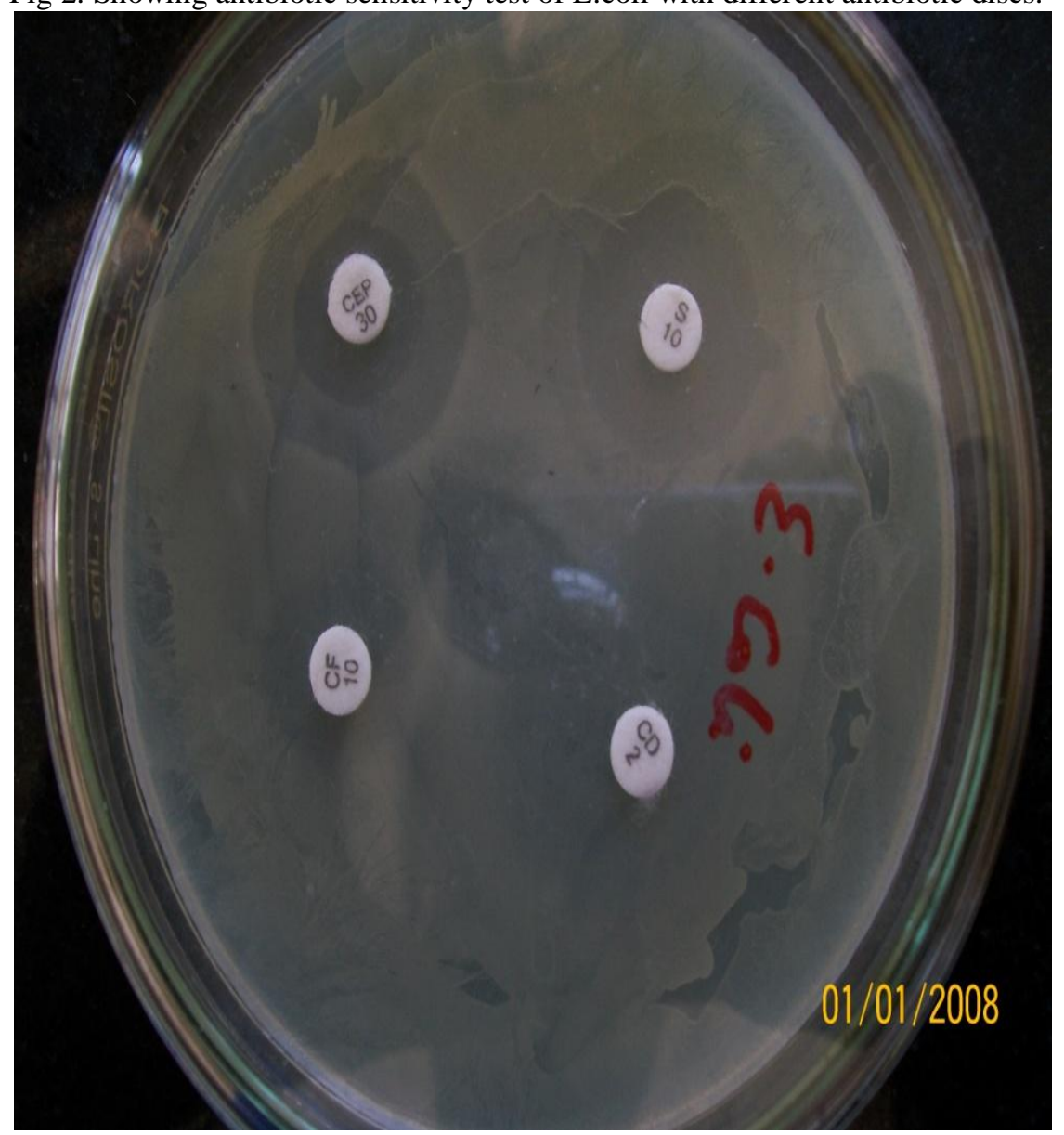

Fig 3.Showing antibiotic sensitivity test of Salmonella spp. with different antibiotic discs.

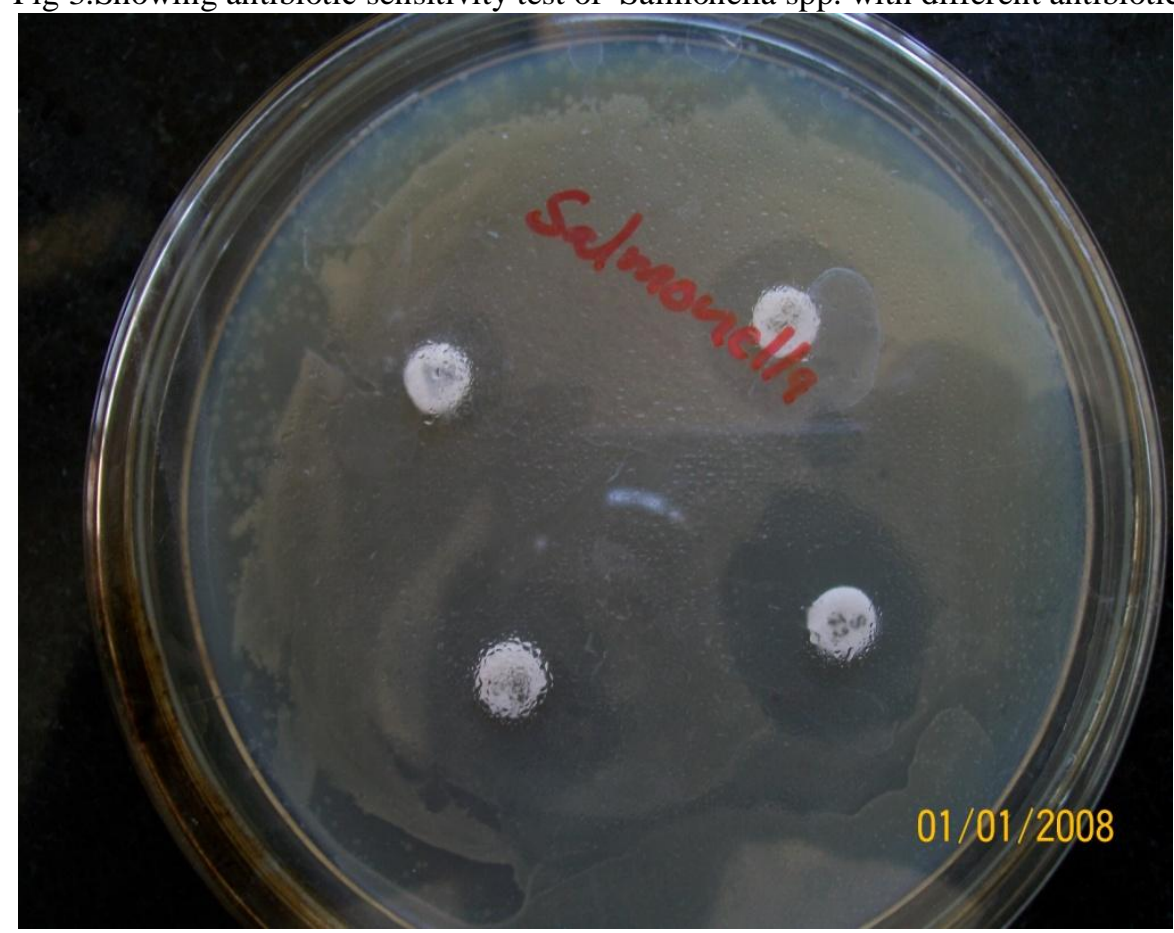


Table 1. Isolation of Salmonella spp., E. coli and S.aureus from different sources of retail meat shops

\begin{tabular}{|c|c|c|c|c|c|c|c|c|}
\hline \multirow[t]{2}{*}{ S. No. } & \multirow[t]{2}{*}{ Source } & \multirow{2}{*}{$\begin{array}{c}\text { No. of } \\
\text { sample } \\
\text { tested }\end{array}$} & \multicolumn{3}{|c|}{ No. of isolates } & \multicolumn{3}{|c|}{ Percentage positive } \\
\hline & & & $\begin{array}{c}\text { Salmonella } \\
\text { spp }\end{array}$ & E.coli & S.aureus & $\begin{array}{c}\text { Salmonella } \\
\text { spp. }\end{array}$ & E.coli & S.aureus \\
\hline 1 & Knife & 15 & 0 & 4 & 6 & 0.00 & 26.67 & 40.02 \\
\hline 2 & Scalding tank & 15 & 1 & 4 & 5 & 6.67 & 26.67 & 33.33 \\
\hline 3 & Defeatherer & 15 & 0 & 5 & 4 & 0.00 & 33.33 & 26.67 \\
\hline 4 & Dressing Table & 15 & 3 & 6 & 8 & 20 & 40.02 & 53.36 \\
\hline 5 & Platform & 15 & 0 & 3 & 7 & 0.00 & 20 & 46.67 \\
\hline 6 & Personnel & 15 & 0 & 02 & 1 & 0.00 & 13.33 & 6.67 \\
\hline 7 & Water & 15 & 1 & 7 & 8 & 6.67 & 46.67 & 53.36 \\
\hline 8 & meat & 15 & 3 & 8 & 7 & 20 & 53.36 & 46.69 \\
\hline & Total & 120 & 8 & 39 & 46 & 6.67 & 32.5 & 38.33 \\
\hline
\end{tabular}

\section{Conclusion:-}

Present study concluded that the meat from retail meat shops is important sources of bacteria of public health significance i.e. Salmonella, E.coli and Staphylococci in Hyderabad city. Presence of this pathogenic microorganisms indicating there is a need to screening of meat from the retail shops to monitor hygienic conditions (Muleta,and Ashenafi, 2001) Thus, it requires strong controlling system of the personal hygiene and educating food handlers about the basic ideas of processing and producing a safe food. In conclusion, the presence of food pathogens and indicator organisms such as thermo-tolerant $E$. coli in most of the retail shops meat samples shows poor food handling and processing practices. Therefore, meat handlers and sellers should be educated on the adverse effects of lack of proper personal, environmental hygiene and sanitation. In addition, consumers should avoid eating raw and inadequately cooked food.

\section{Acknowledgments}

The authors are thankful to Dept.of Veterinary Public Health, C.V.Sc, RJNR and Sri Venkateswara Veterinary University, Tirupati for providing necessary facilities to carry out the research work.

\section{References}

1. Busani L. G., Scavia I., Luzzi and. Caprioli A, (2006). Laboratory surveillance for prevention and control of foodborne zoonoses. Ann. It Super Sanita, 42: 401-04.

2. CDC, (2000). Annual report. CDC/USDA/FDA foodborne disease active surveillance network. CDC's Emerging Infections Program.

3. Collee J.G and Mackie T.J. (1999).Practical Medical Microbiology. Churchill livingstone. 14th ed: 883-884 and 898-907.

4. Farzana K., S. Akhtar and Jabeen F. (2009). Prevalence and antibiotic resistance of bacteria in two ethnic milk based products. Pak J Bot, 41: 935-943.

5. Gibbons I.S., Adesiyun A., Seepersadsingh N., (2006). Rahaman. Investigation for possible source(s) of. contamination of ready-to-eat meat products with Listeria spp. and other pathogens in a meat processing plant in Trinidad. Food Microbiol; 23(4):359-66

6. Haimanot Tassew, Alemseged Abdissa, Getenet Beyene, Solomon Gebre-Selassie : (2010).Microbial flora and food borne pathogens on minced meat and their susceptibility to antimicrobial agents. Ethiop J Health Sci, 20(3):137-143.

7. Kumar A., Shafat S., Gupta H. R., Hakeem Sharma R. (2010). Tracking of spoilage and pathogenic microbes in poultry meat from local retail markets of Jammu. Indian Journal of Poultry Science. 45(1).

8. Lin J., Yeh K.S., Liu H.T., Lin J.H. (2009).Staphylococcus aureus isolated from pork and chicken carcasses in Taiwan: prevalence and antimicrobial susceptibility. J. Food Prot, 72(3):608-612.

9. Morar A., Milovan G., Sala C. (2008). Stanchescu Establishing The Bacterial Control Points In Poultry Slaughterhouse. Lucrari Stiinlifice Medicina Veterinara XLI: 704-407.

10. Morris, G.K. and Wells J. B. (1970). Salmonella contamination in poultry processing plant. Appl. Microbiol. 19 (5): $795-799$.

11. Muleta D,and Ashenafi J. (2001).Salmonella, Shigella and growth potential of other food borne pathogens in Ethiopia street vended foods. East Africa Med J, 78(11):576-580. 
12. Petersen K. E., and James W. O., (1998) Agents, vehicles and causal inference in bacterial foodborne disease outbreaks: 82 reports (1986-1995). J. Am. Vet. Med. Assoc. 212: 1874-1881.

13. Siddiqui F.J., Rabbani F., Hasan R., Nizami S.Q., Bhutta Z.A. (2006).Typhoid fever in children: some epidemiological considerations from Karachi, Pakistan. Int. J. Infect Dis, 10: 215-222.

14. Sousa C.P. (2008).The Impact of Food Manufacturing Practices on Food borne Diseases. Braz arch bioTechnol, 51(4):815-823.

15. Valerie M. B., Checkley S. L., Gensler G. E. and Barrios P. R. (2009). Microbiological baseline study of poultry slaughtered in provincially inspected abattoirs in Alberta, Canada. Can Vet J. 50 (2): 173-178.

16. WHO (2003). The 8th Report of the WHO Surveillance Programme for Control of Foodborne Infections and Intoxications in Europe. WHO, Europe.

17. Zhao C., B. Ge J.D., Villena R., Sudler and Yeh E., (2001). Prevalence of Campylobacter spp., Escherichia coli and Salmonella serovars in retail chicken, Turkey, pork and beef from the Greater Washington D. C., Area. Applied Environ. Microbiol. 67: 5431-5436. 